\title{
High-grade maxillary osteosarcoma: A case report and review of the literature
}

\author{
Ilson Sepúlveda*1, Michael Frelinghuysen ${ }^{2}$, Enrique Platín ${ }^{3}$, Carolina Delgado ${ }^{4}$, M Loreto Spencer ${ }^{4}$ \\ ${ }^{1}$ Oral, Maxillofacial-Head and Neck Radiologist, ENT-Head and Neck Surgery Service, General Hospital of Concepcion, \\ Concepcion, Chile \\ ${ }^{2}$ Physician, Radiation Oncologist, Radiotherapy Department, Oncology Service, General Hospital of Concepcion, Concepcion, \\ Chile \\ ${ }^{3}$ Professor of Oral and Maxillofacial Radiology, University of North Carolina School of Dentistry, Chapel Hill, NC. USA \\ ${ }^{4}$ Physician Pathologist, Pathology Department, General Hospital of Concepción, University of Concepcion School of Medicine, \\ Concepcion, Chile
}

Received: September 24, 2015

Accepted: October 26, 2015

Online Published: October 30, 2015

DOI: $10.5430 /$ crcp.v3n1p14

URL: http://dx.doi.org/10.5430/crcp.v3n1p14

\begin{abstract}
We report the case of a patient who was presented to the Ear, Nose and Throat (ENT) clinic with swelling of the left upper maxillary region. Diagnostic imaging studies revealed an aggressive heterogeneous hyper enhanced solid mass following contrast media administration. A biopsy of the area confirmed the presence of High-grade Osteosarcoma. Subsequently, the patient was treated with surgery and chemotherapy.
\end{abstract}

Key Words: Osteosarcoma, Maxillary, Computed Tomography, Magnetic Resonance Imaging

\section{INTRODUCTION}

Osteosarcoma of the nasal cavity and paranasal sinuses is a relatively rare disorder derived from cells of mesenchymal origin with various histological patterns. Computed Tomography $(\mathrm{CT})$ and Magnetic Resonance Imaging (MRI) scan are useful in defining bone sclerosis, tumor calcifications and involvement of neighboring soft tissues. The surgical resection is the treatment of choise and neoadjuvant chemotherapy improve the survival rates when is not possible to obtain negative surgical margins.

\section{CASE REPORT}

This is a case of a 21-year-old male patient without history of previous diseases, without habits such as smoking or alcohol and drugs consumption, who consulted to the Emergency room due to swelling of the left upper maxillary region. The clinical exam showed bone weakness and then was referred to the Nose and Throat (ENT) clinic where imaging studies were asked for a better characterization of the lesion. Due the size, fast grown of the swelling and bone compromise, it's decided do not perform a conventional $X$ ray exam in concordance with the preliminary diagnosis hypothesis (aggressive maxillary tumor). A head and neck CT exam was performed showing an aggressive, expansive and destructive heterodense solid mass centered in the anterolateral wall of the maxillary sinus and left zygomatic arch (see Figure 1). Enhancement was seen following intravenous contrast administration with central hypodense areas suggestive of necrosis.

\footnotetext{
* Correspondence: Ilson Sepúlveda; Email: isepulvedaguilar@gmail.com; Address: ENT-Head and Neck Surgery Service, General Hospital of Concepcion. San Martin Av; n 1436; Concepcion, Chile.
} 
There was no evidence of cervical lymphadenopathies (see Figure 2).

T2 weighted MRI showed a mildly hyperintense solid mass encompassing the left maxillary sinus (see Figure 3). Fat-saturated T1-weighted and Gadolinium weighted MRI showed a heterogeneous enhanced mass. The mass infiltrated the soft tissues of the ipsilateral genian region and contacted the anterior border of the masseter muscle (see Figure 4).

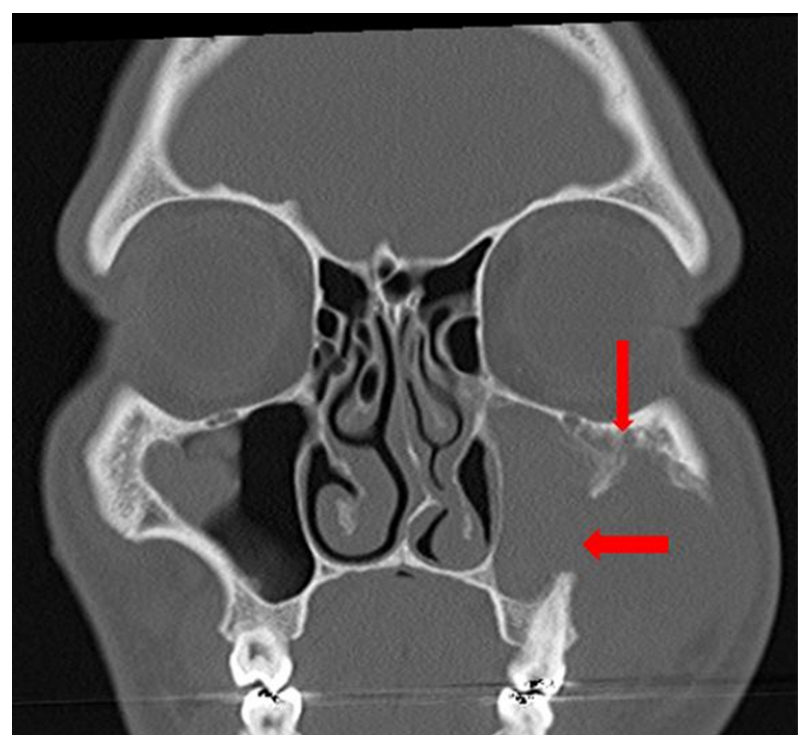

Figure 1. CT bone window. Infiltrative process in the anterolateral wall of the left maxillary sinus (red arrows).

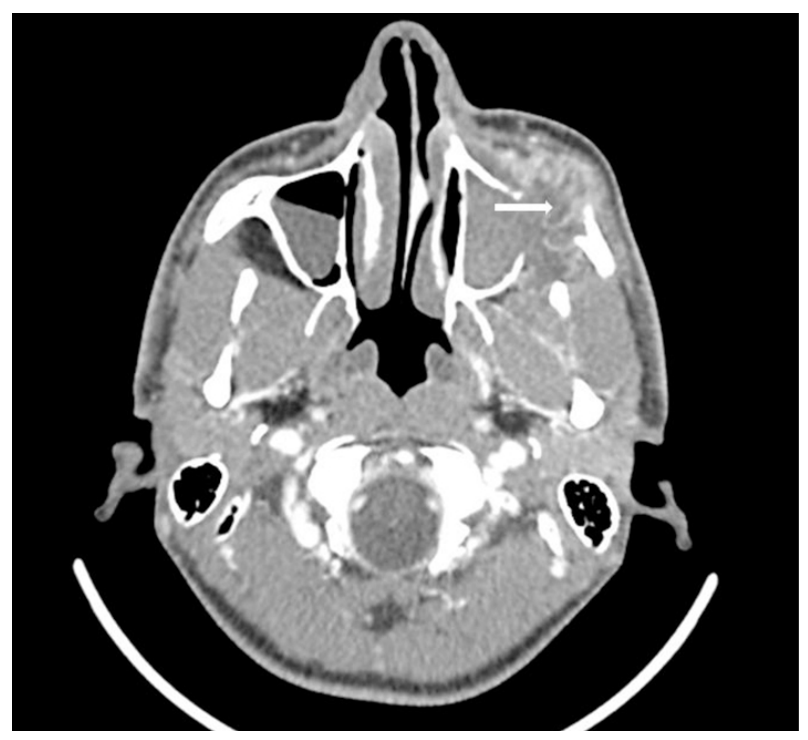

Figure 2. CT soft tissue window following contrast media administration. Central hypodense areas are suggestive of necrosis (white arrow).

A biopsy was performed under general anesthesia revealing wide spread cellular atypia, formation of osteoid tissues, Published by Sciedu Press atypical mitosis and chondroblast differentiation (see Figure 5, Figure 6). Final pathology reported a Fragment of High Grade Osteosarcoma with focal chondroblastic differentiation. The case was reviewed by the Head and Neck Tumor Board (HNTB) and Surgery combined with Chemotherapy was recommended.

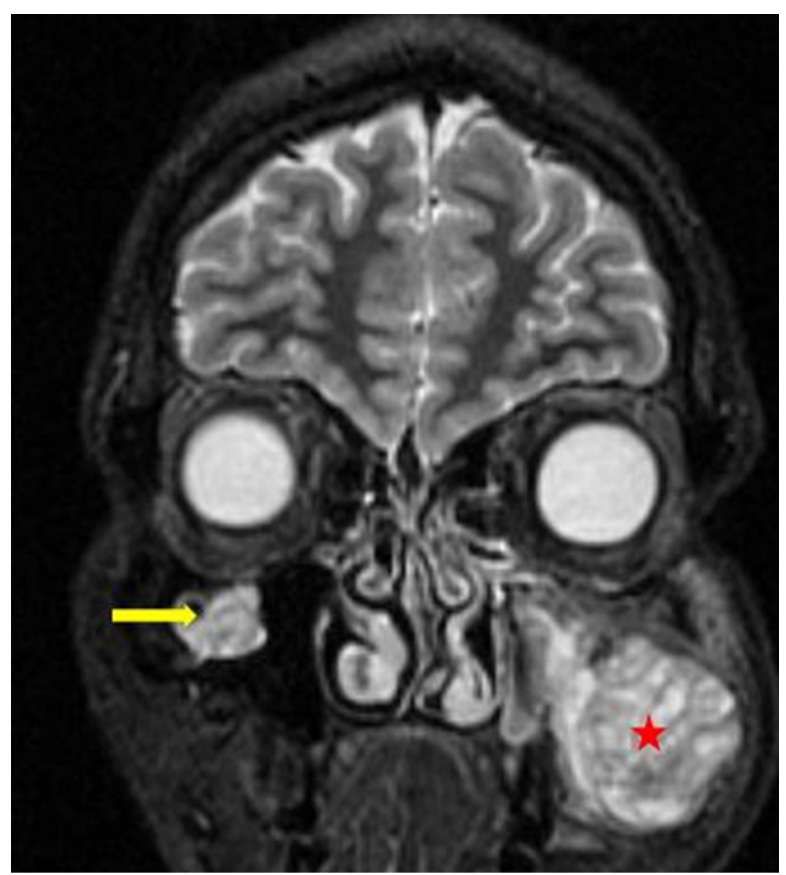

Figure 3. T2-weighted MRI showed a mildly hyperintense solid mass (red star). Mucous retention cyst was observed in the right maxillary sinus (yellow arrow).

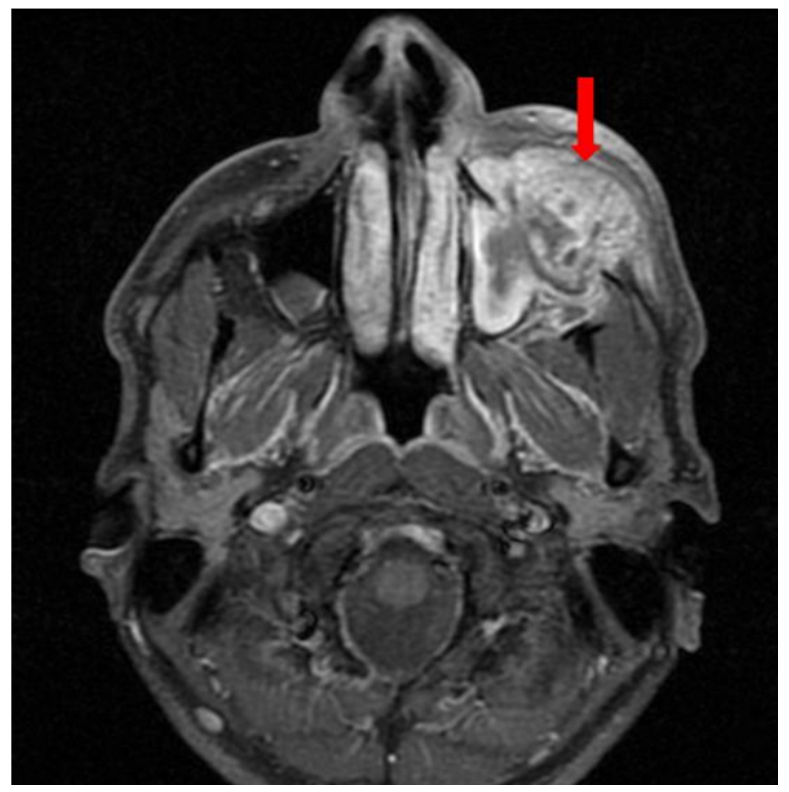

Figure 4. T1 Fast Sat and Gadolinium weighted MRI, heterogeneous enhancement and infiltration of the soft tissues of the genian region (red arrow) 


\section{Discussion}

Osteosarcoma of the jaw (OSJ) is a relatively rare disorder accounting for approximately $6 \%$ of all osteosarcomas $(\mathrm{OS})^{[1]}$ and approximately $0.8 \%$ of oral malignancies. ${ }^{[2]} \mathrm{In}$ the mandible, is most common the Low Grade Osteosarcoma (LOS) that usually presents with a long-standing painless swelling. ${ }^{[1]}$ Primary osteosarcoma of the nasal cavity and paranasal sinuses is rare (encompassing $0.5 \%-1 \%$ of all tumors occurring in this location). It has been estimated that sinonasal osteosarcomas account for approximately $3 \%$ of all OS. ${ }^{[3]}$ They may arise de novo or subsequent to previous irradiation. It can also be seen in pre-existing Paget's disease of the bone and fibrous dysplasia patients. Isolated cases of trauma have been implicated as contributing factors. ${ }^{[4]}$ The risk of developing OS after radiotherapy is between $0.01 \%$ $0.03 \%$ of all irradiated patients. ${ }^{[5]}$ OSJ occurs later in life than osteosarcoma of the long bones peaking in the second, third and fourth decades of life (mean age: 35 ) years. More men than women are usually affected. ${ }^{[6]}$

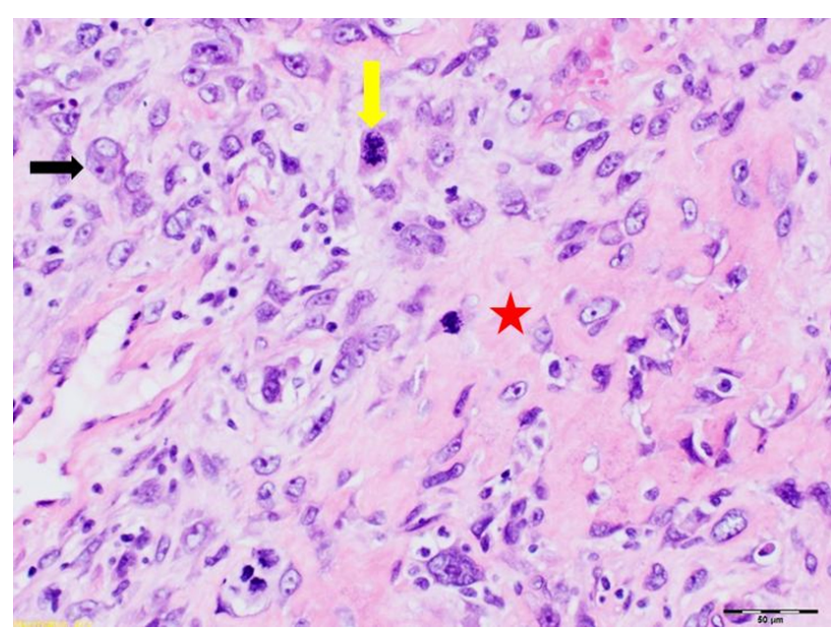

Figure 5. HE Stain. Wide spread cellular atypia (black arrow), formation of osteoid tissues (red star) and atypical mitosis (yellow arrow).

Sarcomas are malignant neoplasms derived from cells of mesenchymal origin. The originating tissues include bone, cartilage, muscle, fibrous, vascular, fatty and neural tissues. OS is attributed to a heterogeneous group of primary malignant neoplasms in which mesenchymal cells produce osteoid or immature bone. ${ }^{[6]}$ The biological behavior of OSJ differs from other tumors of skeletal bones. In OSJ, the average onset of the disease happens 10-20 years later than the onset of long bone tumors. Distant metastasis occurs less frequently and survival rates are higher. ${ }^{[7]}$

OS has a sarcomatous stroma that is produced directly by the tumor cells. Various histological patterns can dominate and have been designated osteoblastic, chondroblastic, and fibroblastic. Chondroblastic osteosarcomas are the most frequently histologic types in the jaws and can be misdiagnosed as chondrosarcoma. ${ }^{[8]}$ Presenting signs and symptoms of OSJ include regional swelling, pain and paresthesia. ${ }^{[1]}$

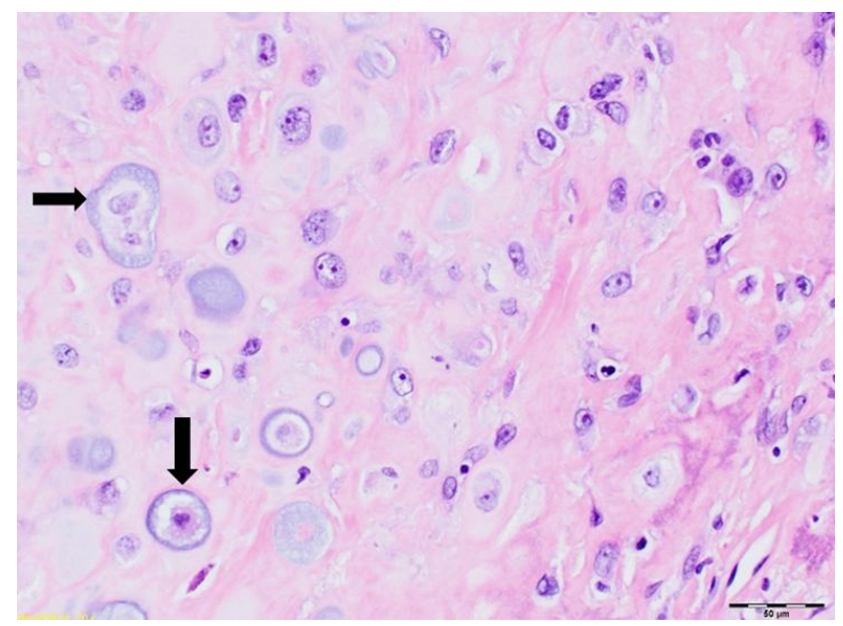

Figure 6. HE Stain. Chondroblast differentiation area (black arrows).

CT scan findings include bone sclerosis and tumor calcifications while MRI is useful in defining involvement of neighboring soft tissues. ${ }^{[5]}$ Basic patterns of ossification seen on a CT scan include the following: No ossification with total absence of bone formation within the tumor consisting of soft tissue alone. Mottled ossification - hyperdense areas of amorphous new bone separated by non-ossified neoplastic tissue and lamellar ossification. New bone formation within the tumor in the form of characteristic bony lamellae that irradiates from a focus like sunburst is typically seen around a central area of osteolysis. Teeth in the involved area frequently show irregular "spiking" and root re-sorption. ${ }^{[9]}$

The differential diagnosis between OS and chondrosarcoma (CS) may be challenging radiographically. Sometimes is not possible to do and could also pose a challenge to histopathology. Generally, the chondrosarcomas are rare in the head and neck region. They appear less aggressive radiographically with less bone destruction and more bone erosion. ${ }^{[10]}$

Similar to OS of the extremities, adequate surgical resection is considered a mainstay of treatment. However, it is more difficult to obtain negative surgical margins because of the complex anatomy in the maxillofacial region. The introduction of neoadjuvant chemotherapy some 25 years ago revolutionized the treatment of extremity osteosarcoma, increasing cure rates from approximately $10 \%$ to $60 \%-70 \%$. The role of chemotherapy in OSJ is less clear and meta-analyses of published data have reported conflicting results. ${ }^{[1]}$ The risk 
of early metastases, particularly in the lung is high with $20 \%$ of all patients with osteosarcoma having metastases when first diagnosed. The rate of micro metastases is estimated to be $80 \%$. Head and neck OS are associated with a lower metastatic rate than are long bone and have a better 5-year survival rate, ranging between $10 \%$ and $85 \% .^{[1]}$

\section{Conclusion}

OS is attributed to a heterogeneous group of primary malignant neoplasms in which mesenchymal cells produce os- teoid or immature bone. OSJ is a relatively rare disorder. Multidisciplinary management, clinical experience and highresolution imaging support are crucial for determining tumor identification, primary tumor localization, and the extent of tumor involvement.

\section{Conflicts of InTEREST Disclosure}

The authors have no conflicts of interest to declare.

\section{REFERENCES}

[1] Ramen S, Chowdhury SKR, Chattopadhyay PK, et al. Low-Grade Osteosarcoma of the Mandible. J. Maxillofac. Oral Surg. 2010; 9: 186-90. PMid: 22190784. http://dx.doi.org/10.1007/s1266 3-010-0057-0

[2] Hirobumi S, Adachi M, Yagishita H, et al. A case of maxillary osteosarcoma with epuloid growth. Asian Journal of Oral and Maxillofacial Surgery. 2011; 23: 153-6. http://dx.doi.org/10.1016/j .ajoms . 2010.11.004

[3] Vlychou M, Ostlere SJ, Kerr R, et al. Low-grade osteosarcoma of the ethmoid sinus. Skeletal Radiol. 2007; 36: 459-62. PMid: 17091307. http://dx.doi.org/10.1007/s00256-006-0231-0

[4] Nirmala SVSG, Sivakumar N, Kishore K, et al. Osteosarcoma of mandible in a 10-year-old girl. Journal of Indian Society of Pedodontics and Preventive Dentistry. 2014; 32: 74-8. PMid: 24531608. http://dx.doi.org/10.4103/0970-4388.127067

[5] Biyas B, Naikmasur VG, Acharya S, et al. Low-grade osteosarcoma of maxilla: Report of a case and review of literature. Journal of Oral and Maxillofacial Surgery, Medicine, and Pathology. 2014; 26: 590-5. http://dx.doi.org/10.1016/j.ajoms.2013.09.006

[6] Peer Wolfgang K, Niloufar S, Nadja VM, et al. Clinical, therapeutic and prognostic features of osteosarcoma of the jaws: Experience of
36 cases. Journal of Cranio-Maxillo-Facial Surgery. 2012; 40: 541-8. PMid: 22082731. http://dx.doi.org/10.1016/j.jcms. 2011 .10 .001

[7] Márcio BA, Ícaro B, Belini FM, et al. Advanced osteosarcoma of the maxilla: A case report. Med Oral Patol Oral Cir Bucal. 2008; 13: 492-5.

[8] Hiroaki S, Kohei O, Toshihide N, et al. Osteosarcoma in the maxilla: a case report. Oral Radiol. 2006; 22: 37-40. http://dx. doi .org /10.1007/s11282-006-0042-y

[9] Musaed A, Alain R, Yoann P, et al. A Rare Case of Radiation-Induced Osteosarcoma of the Ethmoid Sinus. Case Reports in Otolaryngology. 2011: 1-3. PMid: 22937375. http://dx.doi.org/10.1155/201 $1 / 786202$

[10] Wang S, Shi H, Yu Q. Osteosarcoma of the jaws: demographic and CT imaging features. Dentomaxillofacial Radiology. 2012; 4: 37-42. PMid: 22074870. http://dx.doi.org/10.1259/dmfr/868348 44

[11] Sven J, Ulrich M, Jenny P, et al. Craniofacial osteosarcoma Experience of the cooperative German-Austrian-Swiss osteosarcoma study group. Oral Oncology. 2008; 44: 286-294. PMid: 17467326. http: //dx.doi.org/10.1016/j.oraloncology.2007.03.001 